\title{
Application of Switched Reluctance Motor in Vehicle Active Stabilizer Bar
}

\author{
Meng Zhuo ${ }^{1, *}$, Wang Libiao ${ }^{1,2}$, Sun Yize ${ }^{1}$, Guo Lei ${ }^{1}$, and Sun Xudong ${ }^{3}$ \\ ${ }^{1}$ College of Mechanical Engineering, Donghua University, Shanghai 201620, China \\ ${ }^{2}$ College of Mechanical Engineering, Taizhou University, Taizhou 318000, China \\ ${ }^{3}$ Central Queensland University, Rockhampton 4700, Australia
}

Received 4 June 2019; Accepted 11 August 2019

\begin{abstract}
Due to the fixed geometric parameters and structure of vehicle passive stabilizer bar, the corresponding anti-roll moment cannot be provided in real time according to the state of the vehicle body, limiting the improvement of the anti-roll performance of vehicles. In order to improve the anti-roll performance of vehicles, a vehicle roll model, a wheel load transfer model and a finite element calculation model of switched reluctance motor were established respectively in this study. By calculating the vehicle roll and wheel load transfer model, the target anti-roll moment of the active stabilizer bar driven by the switched reluctance motor was obtained to determine the moment requirement of the designed switched reluctance motor, and the finite element method was used to design the corresponding motor. Based on the co-simulation platform of carsim and MATLAB/Simulink, it was verified that the designed active stabilizer bar system driven by the switched reluctance motor can improve the anti-roll performance of vehicles. The results demonstrate that under the condition of double lane change, the active stabilizer bar driven by the switched reluctance motor has a vehicle roll angle range of $-1.2 \sim 1.2^{\circ}$, and the passive stabilizer bar has a roll angle range of $-2.5 \sim 4.7^{\circ}$. Compared with the passive stabilizer bar, the anti-roll performance of active stabilizer bar driven by the switched reluctance motor is improved by about $50 \%$. The proposed method provides a good prospect for optimizing the design of vehicle active stabilizer bar system.
\end{abstract}

Keywords: Switched reluctance motor, Active stabilizer bar, Roll, Finite element method

\section{Introduction}

In order to improve the anti-roll performance of vehicles in the conditions of sharp turn and uneven roads, many techniques have been applied to the vehicle stability control system to reduce the vehicle roll angle and improve the safety, such as passive stabilizer bar, four wheel steering, direct yaw moment control and active front steering technology. Because of simple structure and convenient installation, passive stabilizer bar has been widely used in various types of vehicles. However, passive stabilizer bar has certain defects. Due to the fixed geometric parameters and structure, it can neither change the stiffness nor provide the corresponding anti-roll moment in real time according to the vehicle body [1]. In the case of low designed suspension stiffness, it can not effectively provide the anti-roll moment required by the vehicle body, causing various accidents like rollover. In the case of high suspension stiffness, the entire suspension is too rigid, which will reduce the ride comfort.

As higher demands are raised for ride comfort and safety of vehicels, the active stabilizer bar (ASB) system can output the anti-roll moment needed by a vehicle in real time according to the vehicle parameters and road condition information, thereby improving the anti-roll performance. The ASB has been improved on the basis of the passive stabilizer bar, and it can change the roll stiffness according to the running state of vehicles, thus reducing the roll angle

*E-mail address: mz@dhu.edu.cn

ISSN: 1791-2377 @ 2019 School of Science, IHU. All rights reserved.

doi:10.25103/iestr.124.21 and effectively preventing safety accidents like rollover. The main driving elements of the existing ASB are hydraulic and DC motors [2,3]. Despite the large output torque capacity, the hydraulically actuated ASB has low response speed and inefficient energy conversion. The DC motor-driven ASB can compensate for the deficiency of hydraulic ASB to a certain extent. It has the advantages of rapid response, high sensitivity and good controllability. However, demagnetization may occur due to the temperature rise of the motor used for a long time, resulting in control failure. Therefore, it is an urgent problem to design a new ASB system with rapid response capability depending on the dynamic characteristics of vehicles without considering demagnetization.

Based on the above analysis, since the rotor of the switched reluctance motor (SRM) does not have a permanent magnet or a double salient pole structure on, there is no need to consider demagnetization. Therefore, in the present study, the finite element method is used to design a SRM for the vehicle's ASB, which provides a reference for the development and optimization of ASB system.

\section{State of the art}

The structural limitation of passive stabilizer bar limits the angle of reducing vehicle roll. Therefore, ASB has become a research hotspot in the field of vehicle active safety. At present, researchers have carried out a lot of research on ASB system. The rotary hydraulic pump was applied to the vehicle ASB, and the corresponding feedforward and feedback controllers were designed. The vehicle simulation 
and bench test were carried out, but the technical parameters of the hydraulic pump were not analyzed [4]. Rollover is a serious problem for the safety of heavy-duty vehicles, which can cause huge economic and environmental consequences. Thus, $\mathrm{Vu}$ et al. [5] proposed an electronic servo-hydraulic ASB system based on linear LQR optimal control. The comparative test of three different cases without stabilizer bar, passive stabilizer bar and electronic servo-hydraulic ASB were compared. The results show that electronic servohydraulic ASB can significantly improve the anti-roll performance of heavy-duty vehicles, but there is a response hysteresis loop phenomenon. A fuzzy PI-PD controller was designed, and the anti-roll performance of ASB was simulated based on Simulink. It is found that the designed controller can effectively improve the anti-roll performance of vehicles. However, the designed control system was not used for a corresponding study of the actuator [6]. Kong et al. [7] developed a new hierarchical ASB control system to generate and distribute active anti-roll moment between the front and rear axle ASBs, so that the roll stiffness of the front and rear suspension systems can be changed in real time. However, there was no design explanation for the driving motor of the ASB. An ASB scheme consisting of four hydraulic actuators was proposed, and LQR method was used to design a linear optimal controller of ASB. Compared with passive stabilizer bar, the roll stability of heavy vehicles was improved. However, the control of the servo valve was not analyzed and explained [8]. An electrohydraulic actuator system model of ASB was established. A PID controller was designed to control the roll angle of vehicles. A simulation experiment of vehicle equipped with electro-hydraulic driving ASB was carried out on the cosimulation platform of MATLAB/Simulink and Carsim. The dynamic characteristics were analyzed but not compared with other control methods [9]. Considering the uncertainty of vehicle roll parameters and the possible initial conditional deviation constraints, an adaptive robust control strategy based on the U-K method was proposed for active lateral stabilizers. By using the U-K adaptive robust control scheme, the actual roll angle error quickly converged from the initial error of 0.287 degrees to zero in 0.3 second. However, how to set the adaptive robust control parameters of the U-K method was not clearly specified [10]. In order to balance the roll stability during cornering and the smoothness on a straight road, the body roll angle was controlled by a twochannel ASB controller based on the sliding mode theory. The simulation results show that the designed controller can not only effectively reduce the vehicle roll angle, but also improve the yaw response and steering stability of the vehicle under emergency driving conditions [11]. A self adjusting fuzzy controller was used to control the vehicle roll, and MATLAB/Simulink was employed to carry out the vehicle roll control simulation test. The simulation results were compared with those of the passive anti-roll bar and the conventional fuzzy PID controller. It was proved that the proposed controller can reduce the roll of the vehicle and improve the ride and maneuverability of the passenger car. However, the specific implementation of the control method was not analyzed [12]. According to the coupling relationship between active suspension and $\mathrm{ASB}$, the corresponding controllers of the two systems were designed respectively. The simulation analysis results show that the integrated control can improve the steering stability and smoothness of vehicles. However, the dynamic actuators of ASB were not considered [13]. In order to prevent vehicle rollover and improve ride comfort in the conditions of emergency steering or uneven roads, the controller of ASB was designed based on the linear quadratic optimal control theory. The particle swarm optimization algorithm was used to optimize the weight coefficient of the designed controller. The method effectively avoided vehicle rollover in different driving conditions of the vehicle, but the actuator of the ASB was not described [14]. Gong et al. [15] carried out simulation and actual vehicle test on ASB of hydraulic motor, finding it had better anti-roll characteristics and ride comfort. However, the specific design of hydraulic motor was not analyzed. In the Adams/Car, the vehicle model with ASB was established, and the simulation test was performed on Simulink platform. The ASB with large roll angle stiffness is more helpful to improve the roll stability of vehicles. However, the study failed to analyze the mechanical parameters of ASB considering the roll resistance of the stabilizer bar [16]. In the process of defining the sliding surface of the controller, Guo et al. [17] introduced the fractional calculus theory to design the corresponding controller of ASB. The fuzzy rules were used to adaptively adjust the controller's switching gain parameters to suppress the chattering phenomenon of the sliding mode controller and improve the robustness of the system. However, the drive of the ASB had not been studied. A hydraulic ASB system was proposed, and a sliding mode controller was designed to improve the roll stability of vehicles. Nevertheless, the parameters of the hydraulic power source had not been analyzed [18]. A dynamic model of the ASB system was established, and the PID controller was designed to improve the roll stability of vehicles. The results show that ASB can improve the stability and safety of vehicles compared with the traditional passive stabilizer bar, but the design of the motor was not described [19].

The existing studies mainly focus on the control algorithm of ASB, but there are few studies on the ASB actuator, especially the design analysis of the actuator. In this study, an ASB driven by SRM is proposed, which can provide the corresponding anti-roll moment in real time according to the state information of vehicles, thus improving the anti-roll capability. Based on the mechanical model of vehicle roll and wheel load transfer, the anti-roll moment of the ASB is calculated, and the torque requirement of the designed $\mathrm{SRM}$ is obtained. The corresponding motor is designed by using finite element method.

The remainder of this study is organized as follows. In Section 3, the vehicle roll model is presented, and the SRM applicable to the vehicle ASB is designed based on the finite element analysis method. In Section 4 , the performance of the designed SRM is verified by using the co-simulation platform of CarSim and MATLAB/Simulink. Finally, Section 5 draws the conclusions.

\section{Methodology}

\subsection{Description of SRM Driven ASB System}

As shown in Fig. 1, the ASB system based on SRM drive is composed of a SRM, left and right stabilizer bars, and a deceleration mechanism. The motor and the deceleration mechanism are disposed between the left and right stabilizer bars. The right stabilizer bar is connected to the stator of the motor, and the left stabilizer bar is connected to the output shaft of the decelerator. In this way, the motor can make the left stabilizer bar rotate relatively around the right stabilizer bar. When the vehicle is driving on a sharp turn or on an 
uneven road, the output shaft of the motor produces a rotating motion and is transmitted to the left stabilizer bar through the deceleration mechanism. As a result, the left and right stabilizer bar will produce a relative torsional motion and generate the corresponding additional anti-roll moment effects on the vehicle body, thereby suppressing the roll motion and improving the roll stability of the vehicle.

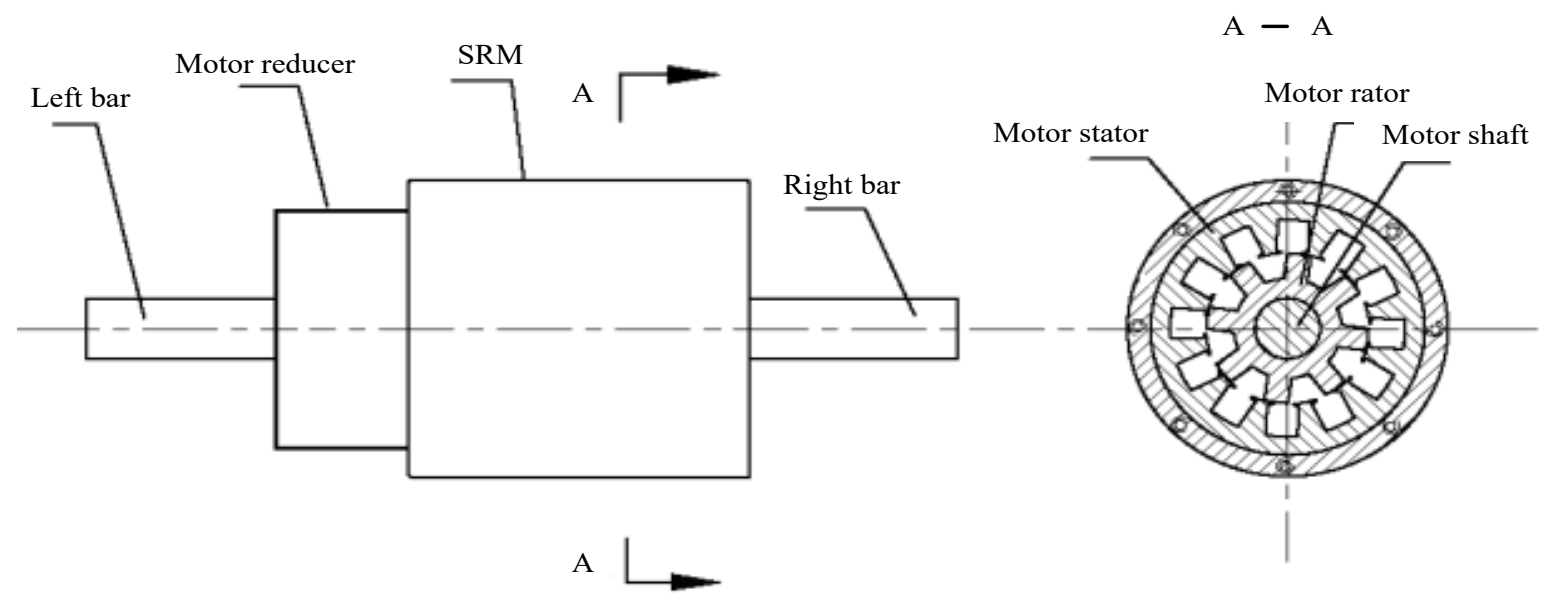

Fig. 1. ASB system based on SRM

\subsection{Target motor torque calculation}

When the vehicle is cornering, the roll motion of the vehicle body relative to the suspension can be seen as a rotational motion about the roll center of the suspension. The roll model of the vehicle is shown in Fig. 2. The lateral acceleration causes the body to generate a roll moment. In order to maintain the stability of the vehicle, the sum of the anti-roll moment generated by the suspension system and the anti-roll moment of the ASB must be balanced with the roll moment generated by the vehicle body. The lateral moment balance equation is as follows:

$$
k_{\varphi f} \varphi+M_{a f}+k_{\varphi r} \varphi+M_{a r}=\mu m_{s} h_{s}+m_{s} h_{s} \varphi
$$

where $m_{s}$ is the sprung mass. $k_{\phi f}$ and $k_{\phi r}$ are the front and rear suspension roll stiffness, respectively. $M_{a f}$ and $M_{a r}$ are the anti-roll moments of the front and rear ASB systems, respectively. $\phi$ is the roll angle. $\mu$ is the lateral acceleration. $h_{s}$ is the distance between body center of mass and roll center.

The torsional sprung of the ASB is connected with the motor in series. When the motor generates torque, the torsion sprung can enhance the stability of the ASB. According to the roll stiffness ratio of the front and rear suspension and Eq.(1), the anti-roll moment equation of the front and rear ASBs is concluded as follows:

$$
\left\{\begin{array}{c}
M_{a r}=\frac{(1-\alpha)}{\alpha} M_{a f} \\
M_{a f}=\alpha \cdot\left[\mu m_{s} h_{s}+\varphi\left(m_{s} h_{s}-k_{\varphi f}-k_{\varphi r}\right)\right]
\end{array}\right.
$$

When the vehicle generates a roll moment, the load will be transferred in the wheel, which can directly influence the steady-state response of the vehicle. Fig. 3 shows the wheel load transfer model. The distribution of the centrifugal force of the sprung mass on the front and rear axles is related to

the distance from the center of sprung mass to the axles. Therefore, the balance equation of wheel load transfer changes on the front and rear axles are as following:

$$
\left\{\begin{array}{l}
k_{\varphi f} \cdot \varphi+M_{a f}=\Delta m_{f} \cdot d_{f}-\frac{\mu m_{s} l_{r}}{l} \cdot h_{f} \\
k_{\varphi r} \cdot \varphi+M_{a r}=\Delta m_{r} \cdot d_{r}-\frac{\mu m_{s} l_{f}}{l} \cdot h_{r}
\end{array}\right.
$$

where $\Delta m_{f}$ and $\Delta m_{r}$ are the front and rear axles wheel load transfer amount, respectively. $d_{f}$ and $d_{r}$ are the front and rear axles. $h_{f}$ and $h_{r}$ are the roll center distances of front and rear axles, respectively. $l_{f}$ and $l_{r}$ are the distance from the center of mass to the front and rear axles. $l$ is the wheelbase of the vehicle.

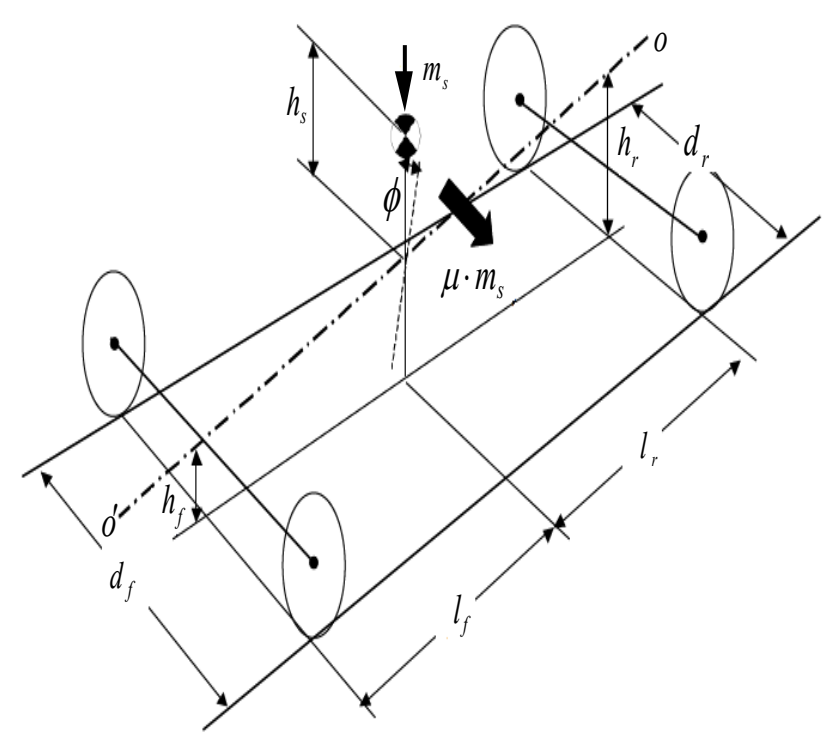

Fig. 2. Vehicle roll model 
From Eq. (3), the wheel loads on the front and rear axles can beexpressed as below:

$$
\left\{\begin{array}{l}
\Delta m_{f}=\frac{k_{\varphi f} \cdot \varphi+M_{a f}}{d_{f}}+\frac{\mu m_{s} l_{r}}{d_{f} \cdot l} \cdot h_{f} \\
\Delta m_{r}=\frac{k_{\varphi r} \cdot \varphi+M_{a r}}{d_{r}}+\frac{\mu m_{s} l_{f}}{d_{r} \cdot l} \cdot h_{r}
\end{array}\right.
$$

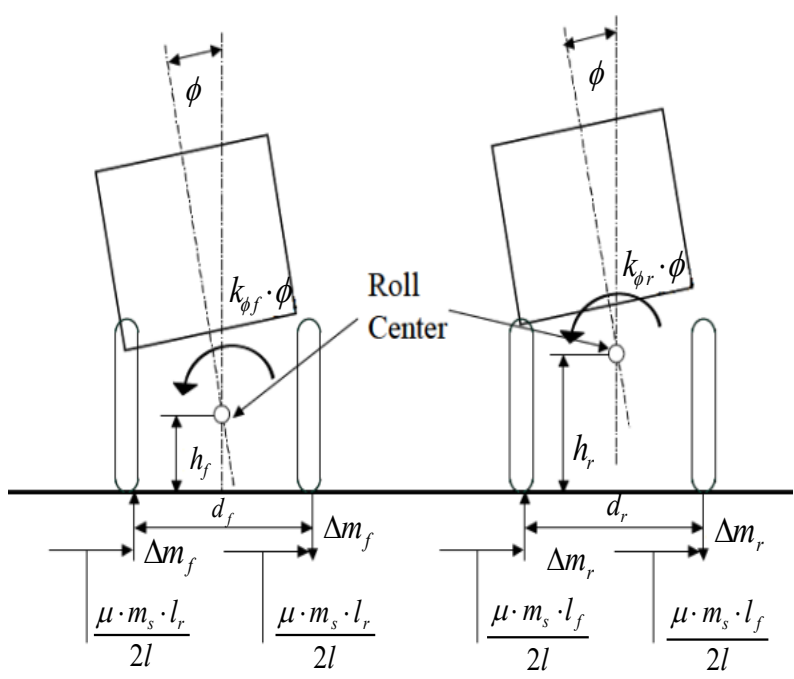

Fig. 3. Wheel load variation model

Considering the load distribution ratio coefficient of the front and rear axles, the variations of wheel load on the axles have the following relationship:

$$
\left\{\begin{array}{l}
\Delta m_{f}^{\prime}=\beta\left(\Delta m_{f}+\Delta m_{r}\right) \\
\Delta m_{r}^{\prime}=(1-\beta)\left(\Delta m_{f}+\Delta m_{r}\right)
\end{array}\right.
$$

In consideration of the uneven load distribution on front and rear axles, the following equation is obtained by substituting Eq. (5) into Eq. (3):

$$
\left\{\begin{array}{l}
M_{a f}^{\prime}=\Delta m_{f}^{\prime} \cdot d_{f}-\frac{\mu m_{s} l_{r}}{l} \cdot h_{f}-k_{\varphi f} \cdot \varphi \\
M_{a r}^{\prime}=\Delta m_{r}^{\prime} \cdot d_{r}-\frac{\mu m_{s} l_{f}}{l} \cdot h_{r}-k_{\varphi r} \cdot \varphi
\end{array}\right.
$$

The force schematic diagram of the front axle ASB system is shown in Fig. 4. The relationship between the output torque of the front and rear axles ASBs and the anti-roll moment can be concluded as follows:

$$
\left\{\begin{array}{l}
F_{f}=\frac{m_{a f}}{b_{f}}=\frac{M_{a f}^{\prime}}{a_{f}} \\
F_{r}=\frac{m_{a r}}{b_{r}}=\frac{M_{a r}^{\prime}}{a_{r}}
\end{array}\right.
$$

$$
\left\{\begin{array}{l}
m_{a f}=\frac{b_{f}}{a_{f}} M_{a f}^{\prime}=\gamma_{f} M_{a f}^{\prime} \\
m_{a r}=\frac{b_{r}}{a_{r}} M_{a r}^{\prime}=\gamma_{r} M_{a r}^{\prime}
\end{array}\right.
$$

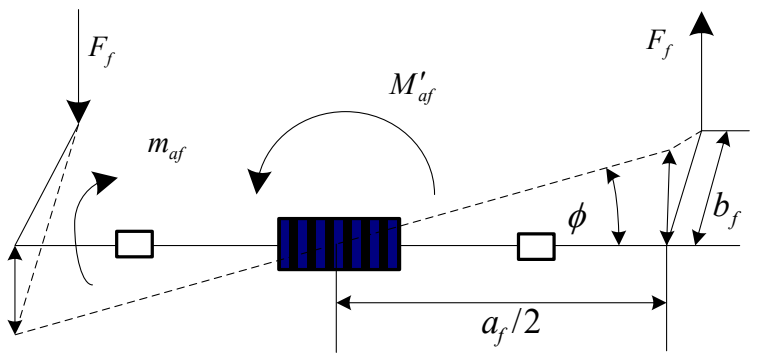

Fig. 4. Mechanical model of front ASB

Considering the transmission ratio of speed reduction mechanism $i$, the output torque of the SRM driver can be obtained:

$$
\left\{\begin{array}{l}
T_{e f}=m_{a f} / i \\
T_{e r}=m_{a r} / i
\end{array}\right.
$$

where $a_{f}$ and $a_{r}$ are the lenghth of stabilizer bars on the front and rear axles. $b_{f}$ and $b_{r}$ are the lenghth of the stabilizer lever arm of front and rear axles, respectively. $\gamma_{f}$ and $\gamma_{r}$ are the ratios of the length of the stabilizer arm to the stabilizers on the front and rear axles, respectively. $m_{a f}$ and $m_{a r}$ are the output torque of the ASB systems on the front and rear axles, respectively. $T_{e f}$ and $T_{e r}$ are the output torque of the stabilizer bar motors on the front and rear axles.

Table 1. List of vehicle parameters

\begin{tabular}{c|c|c|c}
\hline Parameter/Unit & Quantity & Parameter/Unit & Quantity \\
\hline$m_{s}(\mathrm{~kg})$ & 1762 & $l_{f}(\mathrm{~m})$ & 1.304 \\
$\varphi(\mathrm{rad})$ & $(0 \sim 0.0698)$ & $l_{r}(\mathrm{~m})$ & 1.546 \\
$h_{s}(\mathrm{~m})$ & 0.452 & $d_{f}(\mathrm{~m})$ & 1.536 \\
$\mu\left(\mathrm{m} / \mathrm{s}^{2}\right)$ & $(0 \sim 10)$ & $d_{r}(\mathrm{~m})$ & 1.546 \\
$l(\mathrm{~m})$ & 2.85 & $h_{f}(\mathrm{~m})$ & 0.084 \\
$k_{\varphi f}(\mathrm{Nm} / \mathrm{rad})$ & 48380 & $h_{r}(\mathrm{~m})$ & 0.09035 \\
$k_{\varphi r}(\mathrm{Nm} / \mathrm{rad})$ & 44330 & $\alpha$ & 0.52 \\
$\gamma_{f}$ & 0.301 & $\beta$ & 0.60 \\
$\gamma_{r}$ & 0.195 & $i$ & 160 \\
\hline
\end{tabular}

Through the Eq. (2) to Eq. (9) and the vehicle parameters listed in Table 1, the motor output torque curves of the front and rear axle ASBs are calculated, as shown in Fig. 5. The maximum torque of the target motors on the front and rear axles are $2.88 \mathrm{Nm}$ and $1.66 \mathrm{Nm}$, respectively. 


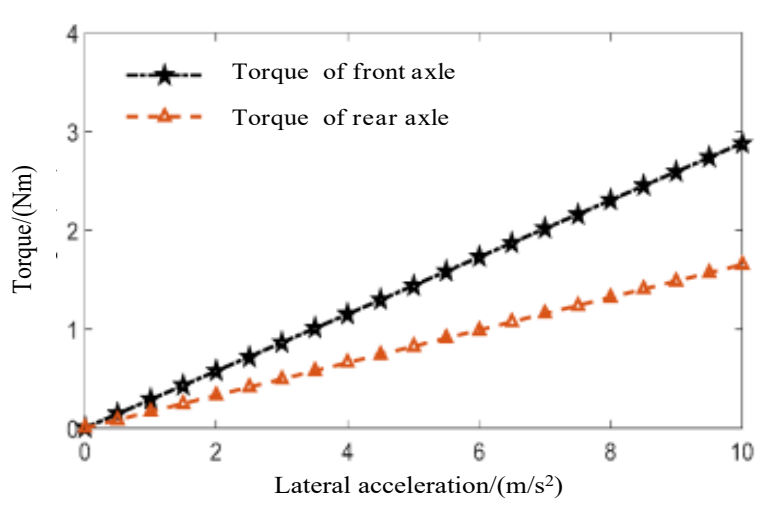

Fig. 5. Diagram of target motor torque

\subsection{Motor design using Finite Element Method}

From section 3.2, it is calculated that the minimum torque of the motor is not less than $2.88 \mathrm{Nm}$ under the power supply of the vehicle battery. Therefore, the motor is designed with the rated rotational speed of $1500 \mathrm{r} / \mathrm{min}$. Based on the empirical design formula, the initial parameters of the prototype are obtained, and the finite element analysis optimization is performed by magnetic field analysis software. Finally, the desired prototype is obtained.

The main parameters of the initial prototype of the SRM are obtained by the following formula [20]:

$$
D^{2} l=\frac{6.1}{B A} \cdot \frac{k_{i}}{k_{m}} \cdot \frac{P_{e}}{n}
$$

where $D$ is the rotor diameter. $l$ is the armature calculation length. $B$ is the maximum flux linkage. $A$ is the electric load. $k_{i}$ is the peak current coefficient. $k_{m}$ is the square wave current coefficient. $P_{e}$ is the rated power. $n$ is the rated speed.

Based on the initial prototype parameters, the model is built in Ansoft MAXWELL and its structure is optimized by carrying out magnetic field finite element analysis In order to be consistent with the actual motor, the simulation analysis is performed by specially adopting a threedimensional finite element model. Fig. 6 shows the magnetic field finite element analysis results of the prototype. The setting of the motor boundary and the solution of the mesh are described in Fig. 6(a). Fig. 6(b) presents the magnetic flux density after the solution. In order to realize better torque output capability below the rated speed, the mechanical characteristics of the designed motor are analyzed. The results are shown in Fig. 7.

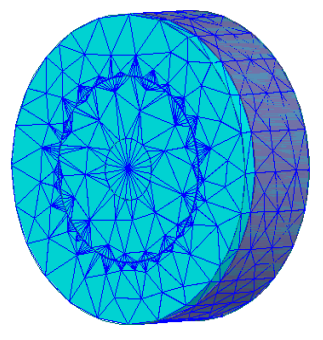

(a) Mesh map

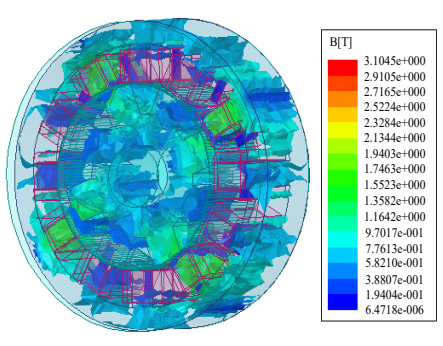

(b) Magnetic flux density cloud
Fig. 6. 3D finite element simulation analysis

Fig. 7 shows that the torque output capability of the motor drops faster when the speed exceeds the rated speed.
However, when the rotation speed is at or below the rated rotation speed, the motor has a better torque output capability. In this case, the torque is $3.6 \mathrm{Nm}$ at the rated rotation speed, which meets the target torque design requirements.

In Fig. 8, the torque output performance of the motor is tested under the voltage of $12 \mathrm{~V}, 15 \mathrm{~V}$ and $17 \mathrm{~V}$, respectively. When the voltage is $12 \mathrm{~V}$, the average output torque of the motor is still about $4 \mathrm{Nm}$, which satisfies the minimum target torque of $2.88 \mathrm{Nm}$. Therefore, the designed SRM satisfies the design requirements for working under the vehicle voltage, and it is applicable to the ASB system.

The prototype motor parameters are shown in Table 2.

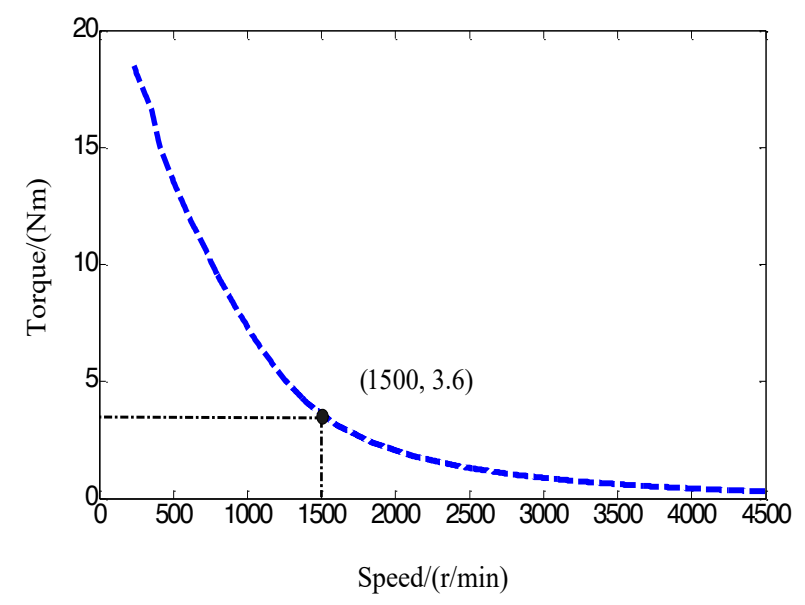

Fig. 7. Mechanical characteristics of motor

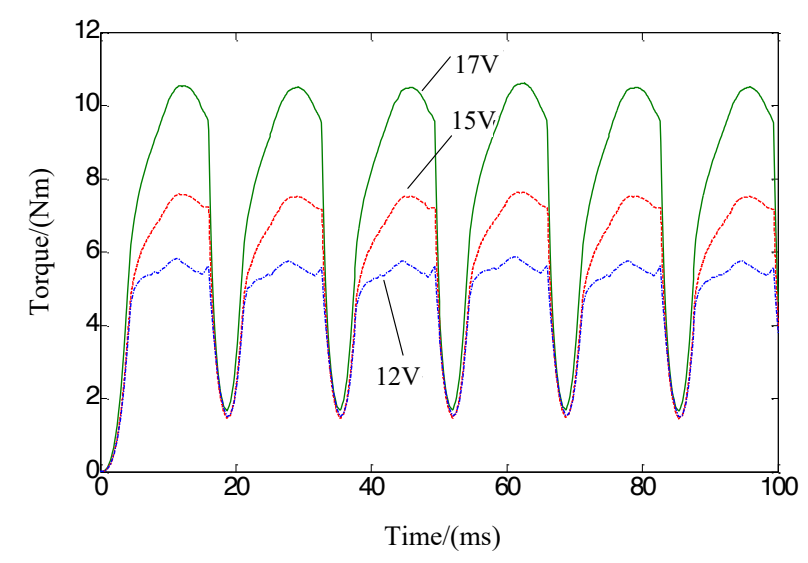

Fig. 8. Output torque curve of motor

Table. 2. List of SRM parameters

\begin{tabular}{c|c|c|c}
\hline $\begin{array}{c}\text { Motor } \\
\text { parameter/Unit }\end{array}$ & Quantity & $\begin{array}{c}\text { Motor } \\
\text { parameter/Unit }\end{array}$ & Quantity \\
\hline Rated voltage/V & 12 & $\begin{array}{c}\text { Rated } \\
\text { speed/(r/min) }\end{array}$ & 1500 \\
\hline Rated power/W & 600 & $\begin{array}{c}\text { Core stack } \\
\text { length/mm }\end{array}$ & 70 \\
\hline $\begin{array}{c}\text { Stator pole } \\
\text { number }\end{array}$ & 12 & Stator arc/rad & 11.51 \\
\hline $\begin{array}{c}\text { Rotor pole } \\
\text { number }\end{array}$ & 8 & $\begin{array}{c}\text { Rotor pole } \\
\text { arc/rad }\end{array}$ & 12.04 \\
\hline $\begin{array}{c}\text { Stator Outer } \\
\text { diameter/mm }\end{array}$ & 102 & $\begin{array}{c}\text { Stator yoke } \\
\text { height/mm }\end{array}$ & 7.5 \\
\hline $\begin{array}{c}\text { Rotor outer } \\
\text { diameter/mm }\end{array}$ & 50.7 & $\begin{array}{c}\text { Rotor yoke } \\
\text { height/mm }\end{array}$ & 10 \\
\hline $\begin{array}{c}\text { Air gap } \\
\text { length/mm }\end{array}$ & 0.4 & $\begin{array}{c}\text { Rotor shaft } \\
\text { diameter/mm }\end{array}$ & 20 \\
\hline
\end{tabular}




\section{Result Analysis and Discussion}

In order to verify the design of the ASB driven by SRM to improve the anti-roll effect of the vehicle, a simulation experimental is conducted. Fig. 9 shows the integrated simulation environment for the integrated vehicle control system with the ASB driven by SRM. First of all, the fluxcurrent-angle spectrum data of the motor is obtained through Ansoft MAXWELL software, and imported into the SRM model in MATLAB/Simulink. An ASB model based on SRM drive is established. Second, based on the vehicle parameters in Table 1, a complete vehicle model with ASB torque input is established in CarSim, and the ASB model and CarSim vehicle model are linked to the vehicle control system. Finally, the data link between different simulation systems is realized through the standardized interface, and the anti-roll experimental of the active suspension vehicle driven by the SRM is completed.

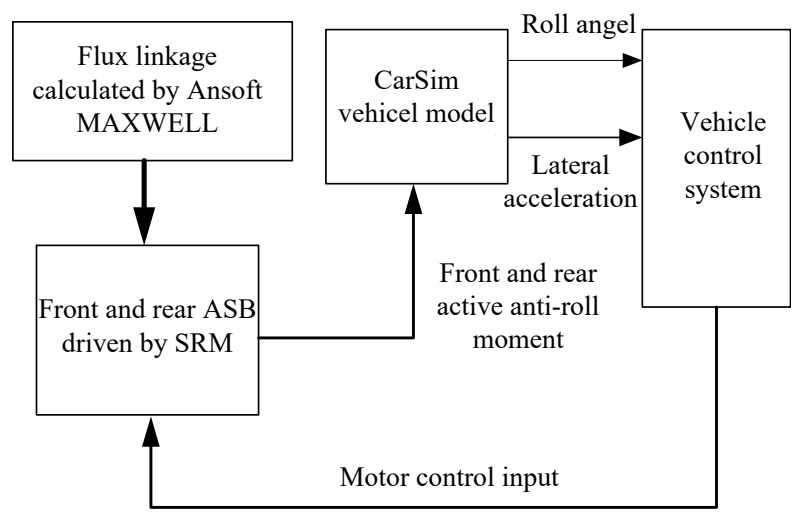

Fig. 9. System unified simulation environment

The vehicle is assumed to drive at a constant speed of 50 $\mathrm{km} / \mathrm{h}$ on the B-type road surface, and the simulation analysis experiment is carried out under the double lane change condition. Fig. 10 shows the curve of the steering input of the front wheel. Fig. 11 describes the curve of the output moment of the ASB driven by the SRM on the front and rear axles in the front wheel angle input of Fig. 10.

As can be seen from the Fig.11, the ASB system on the front and rear axles can output the corresponding torque performance according to the body roll state in real time, which means that the vehicle with ASB driven by SRM has good transient response characteristics.

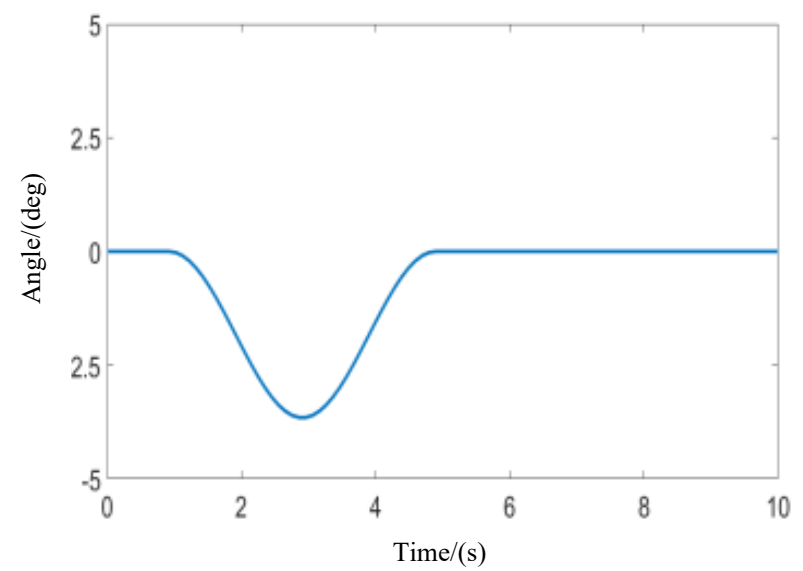

Fig. 10. Vehicle front wheel steering input curve

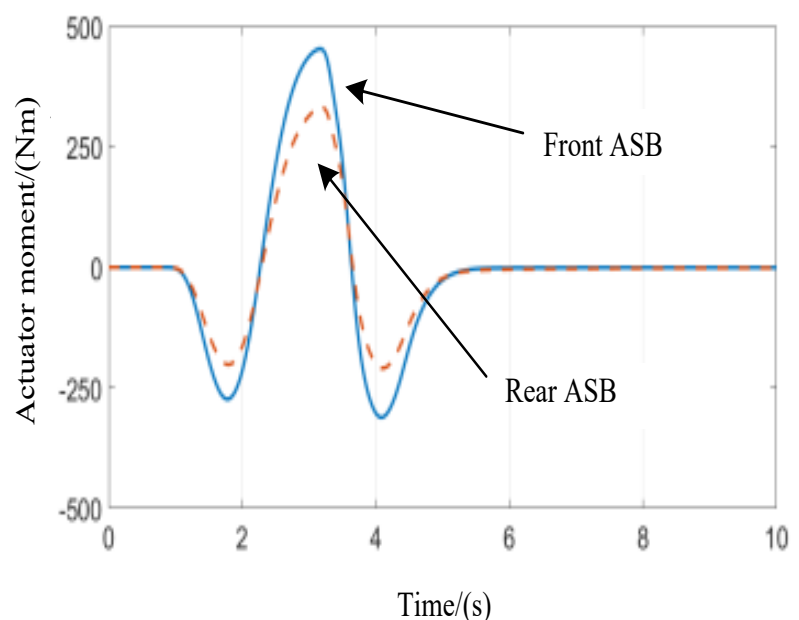

Fig. 11. Output curve of anti-roll moment of front and rear axis of ASB driven by SRM

In Fig. 12, output curves of the vehicle roll angle of ASB with SRM and conventional passive stabilizer bar are shown. It can be seen from the figure that the maximum roll angle of the vehicle controlled by the ASB of the SRM is about 1.2 degrees, while the maximum roll angle of the vehicle controlled by the passive stabilizer bar is about 4.7 degrees. In addition, it can be seen from the figure that the ASB system driven by the SRM makes the transition state of the vehicle roll angle curve smoother, and improves the anti-roll performance and ride comfort of the vehicle effectively.

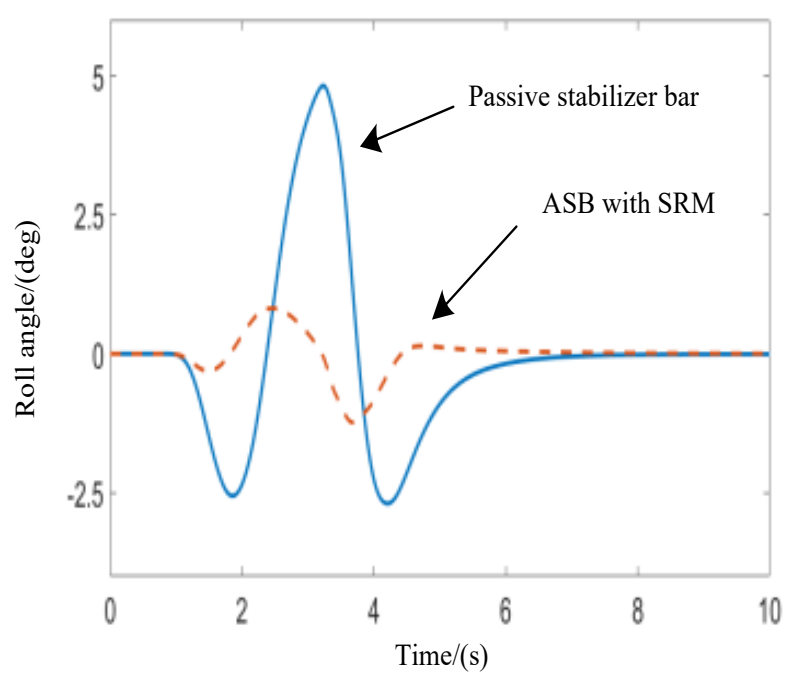

Fig. 12. Vehicle roll angle under the action of ASB driven with SRM and passive stabilizer bar

Fig. 13 demonstrates a phase trajectory diagram of the vehicle roll motion. When the vehicle is running in a double lane change mode, the ASB driven by SRM has a vehicle roll angle range of -1.2 to $1.2^{\circ}$, and the passive stabilizer bar has a roll angle range of -2.5 to $4.7^{\circ}$. Compared with the passive stabilizer bar, the anti-roll performance of ASB based on SRM is improved by about $50 \%$. According to the simulation experiment results, compared with the passive stabilizer system, the ASB driven by SRM designed in this study can not only effectively reduce the vehicle roll angle, but also improve the anti-roll dynamic response performance and the anti-roll stability of the vehicle. 


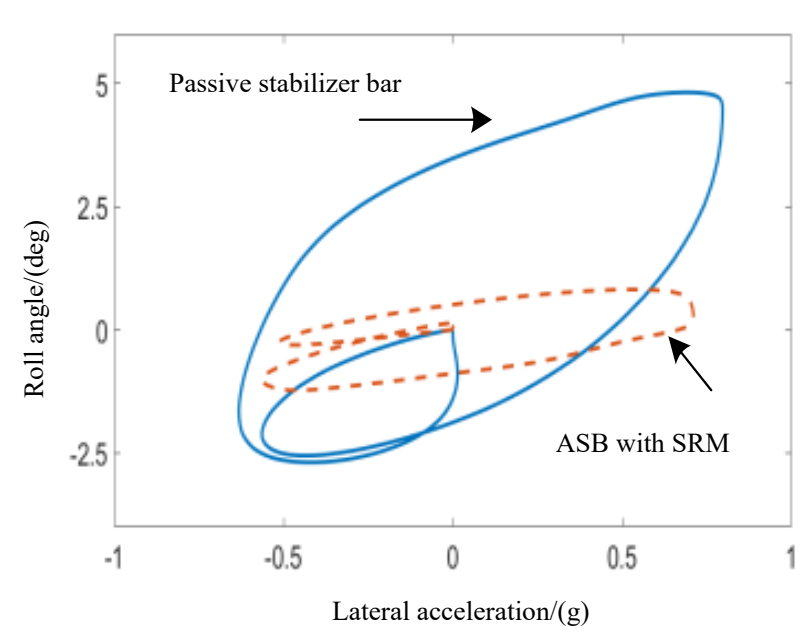

Fig. 13. Vehicle roll phase trajectory under the action of ASB with SRM and passive stabilizer bar

\section{Conclusions}

In order to overcome the problems of slow response and demagnetization of the existing hydraulic and DC motor type ASBs, an ASB driven by SRM was designed to improve the anti-roll performance of vehicle. By establishing the mechanical model of vehicle roll and wheel load transfer, the anti-roll moment of ASB was calculated, and the target rated torque of the designed SRM was obtained. The corresponding SRM was designed by finite element method. On the basis of the co-simulation platform of CarSim and Matlab/Simulink, the anti-roll performance of the vehicle with ASB driven by SRM and passive stabilizer bar was compared. The following conclusions can be drawn:

(1) The roll angle of the vehicle was inversely proportional to the output moment curve of the ASB driven by SRM.
(2) Compared with the passive stabilizer bar, when the front wheel angle of the vehicle was input according to the double lane change condition, the roll angle curve transition of the vehicle with the ASB driven by SRM was smoother, indicating better ride comfort.

(3) When the vehicle was running under the double lane change condition, the ASB driven by SRM had a vehicle roll angle range of -1.2 to $1.2^{\circ}$, and the passive stabilizer bar had a roll angle range of -2.5 to $4.7^{\circ}$. Compared with the passive stabilizer bar, the anti-roll performance of the ASB driven by SRM was improved by $50 \%$ approximately, which demonstrates that the ASB driven by SRM could improve the anti-roll performance of vehicle.

In this study, a new ASB system driven by SRM was designed by establishing a vehicle roll model based on the finite element method. The design of ASB driven by SRM has certain engineering significance for improving the antiroll performance of vehicles in practice. However, due to the lack of relevant real vehicle test platform, the designed system can not be verified by real vehicle test. Therefore, in future research, an actual vehicle test platform will be built to further optimize the structure and parameters of the SRM driven ASB system, so that the designed system can be better applied to engineering practice to improve the anti-roll performance of vehicles.

\section{Acknowledgements}

This work was supported by the Natural Science Foundation of Zhejiang Province, China (Grant No. LY17E050004).

This is an Open Access article distributed under the terms of the Creative Commons Attribution License

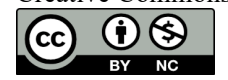

\section{References}

1. Kong, Z., Pi, D. W., Wang, X., "Design and evaluation of a hierarchical control algorithm for an electric active stabilizer bar system". Strojniki Vestnik-Journal of Mechanical Engineering, 62(10), 2016, pp. 565-576.

2. Wu, X. J., Zhou, B., Wen, G. L., "Hydraulically inter-connected suspension anti-roll control research". China Journal of Highway \& Transport, 31(3), 2018, pp. 123-132.

3. Song, C., Xia, C. G., Pan, D. Y., "Research on the control of a new switch-type active anti-roll bar device". Automobile Technology, 15(9), 2018, pp. 56-62.

4. Kim, S., Park, K., Song, H., Hwang, Y., Moon, S., Ahn, H., "Development of control logic for hydraulic active roll control system”. International Journal of Automotive Technology, 13(1), 2015, pp. 87-95.

5. Vu, V. T., Sename, O., Dugard, L., Gaspar, P., "Active anti-roll bar control using electronic servo valve hydraulic damper on single unit heavy vehicle". Ifac Papersonline, 49(11), 2016, pp. 418-425.

6. Muniandy, V., Samin, P. M., Jamaluddin, H., "Application of a selftuning fuzzy PI-PD controller in an active anti-roll bar system for a passenger car". Vehicle System Dynamics, 53(11), 2015, pp. 16411666.

7. Kong, Z. X., Pi, D. W., Chen, S., "Design and simulation of hierarchical control algorithm for electric active stabilizer bar system". In: 2016 International Conference on Chinese Control and Decision Conference, Yinchuan, China: IEEE, 2016, pp. 60696074.

8. Vu, V. T., Sename, O., Dugard, L., Gaspar, P., "Enhancing roll stability of heavy vehicle by LQR active anti-roll bar control using electronic servo-valve hydraulic actuators". Vehicle System Dynamics, 55(9), 2017, pp. 1-25.
9. Park, H. G., Jeong, K. H., Park, M. K., "Electro hydrostatic actuator system based on active stabilizer system for vehicular suspension systems". International Journal of Precision Engineering and Manufacturing, 19(7), 2018, pp. 993-1001.

10. Sun, H., Chen, Y. H., Zhao, H., "Adaptive robust control methodology for active roll control system with uncertainty". Nonlinear Dynamics, 92(2), 2018, pp. 359-371.

11. Yan, M., Pi, D., Li, Y., Wang, H., Wang, E., "The design of anti-roll moment distribution for dual-channel active stabilizer bar system". In: 2018 International Conference on Chinese Control and Decision Conference, Shenyang, China: IEEE, 2018, pp. 63016308.

12. Abushaban, M. H., Abuhadrous, I. M., Sabra. M. B., "A new fuzzy control strategy for active suspensions applied to a half car model". Journal of Mechatronics, 1(2), 2013, pp. 1-7.

13. Zhou, B., Yan, B. C., Lu, X. N., "Coordinated control of vehicle yaw and roll stability based on ars and afs". Journal of Vibration and Shock, 34(18), 2015, pp. 111-117.

14. Chen, S., Xia, C. G., Pan, D. Y., Tao, J. Z., "A study on hybrid rollover control of vehicle with active anti-roll bar". Automotive Engineering, 39(6), 2017, pp. 65-72.

15. Gong, J. S., Li, Y. L., Tian, D. L., Pi, D. W., "Design of hydraulic system used for active lateral stabilizer bar experimental bench". Fluid Power Transmission \& Control, 81(2), 2017, pp.810 .

16. Shi, B. J., Liu, D. H., Li, Z. Y., "Parameterized analysis and optimization of vehicle anti-roll bar". Journal of South China University of Technology (Natural Science Edition), 44(6), 2016, pp. 98-104. 
17. Guo, C. H., Su, X. P., Miao, X. D., "Fuzzy fraction sliding mode control method for active anti-roll bar in vehicle steering system". Mechanical Science and Technology for Aerospace Engineering, 38(07), 2019, pp. 1019-1023.

18. Kong, Z. X., Pi, D. W., Wang, X. H., Wang, H. L., Chen, S., "Design of vehicle hydraulic active stabilizer bar and its control algorithm". Journal of Shandong University (Engineering Science), 47(1), 2017, pp. 104-111.
19. Huang, K., Pan, Y., Zhao, P., "Modeling and experimental analysis of an active anti-roll system". China Mechanical Engineering,28(22), 2017, pp. 2701-2706+2731.

20. Sheng, Z. Y., Pei, X. Q., Zhou, Y. J., "The design scheme and simulation of the wide speed regulation hub motor used in electrical vehicle". Small \& Special Electrical Machines, 45(2), 2017, pp. 1317. 